\title{
Collective Testimony and Collective KnOWLedge
}

\author{
PAUL FAULKNER \\ University of Sheffield
}

$\mathrm{T}$ ESTIMONY is a source of knowledge. On many occasions, the explanation of one's knowing that $\mathrm{p}$ is that a speaker, $\mathrm{S}$, told one that $\mathrm{p}$. Our testimonial sources - the referents of ' $S$ ' - can be other individuals, and they can be collectives; that is, in addition to learning from individuals, we learn things from committees, commissions, councils, clubs, teams, research groups, departments, administrations, churches, states and other social groups. North Korea might make a declaration about its missile programme, the church about the ordination of women priests, the council about its deficit, the research group about its findings, and so on. We will look at a few examples in detail shortly, but the starting point is that social groups can be a source of testimony, and we can learn things from such collective testimony. The question this paper pursues is, what explains our learning that $p$ from collective testimony to $p$ ?

This question should be clarified in three ways. First, in discussing collective testimony one must distinguish metaphysical from epistemological questions. There are metaphysical questions concerning the nature of collectives, and collective agency. ${ }^{1}$ And there is the metaphysical question of whether a collective can be a testifier. I assume a minimal positive answer to this question in assuming that testimonial sources can be collectives. ${ }^{2}$ The question pursued is then epistemological rather than metaphysical. Second, the epistemological question is what grounds our testimonial knowledge that $p$, or grounds the testimonial justification we have for our belief that $\mathrm{p}$. I put aside the prior epistemological question of what makes it reasonable to accept a piece of collective testimony to $\mathrm{p}$ in the first place. ${ }^{3}$ Third, different answers to the central epistemological

1. On the nature of collectives and collective agency, see, for instance, Gilbert (1989), List and Pettit (2011) and Tuomela (2013).

2. For argument, see Tollefsen (2007)

3. I argue for the importance of this distinction in Faulkner (2000).

Contact: Paul Faulkner < paul.faulkner@sheffield.ac.uk> 
question of what explains our learning that $p$ from collective testimony to $p$ then develop and employ different collective notions, where an important distinction is between those answers that make essential reference to a knowing collective and those that do not. Call these positions respectively eliminativist and non-eliminativist. ${ }^{4}$ The disagreement between these theories is over whether or not the introduction of collective testimony into the epistemology of testimony entails the introduction of collective knowers.

A good way of approaching this question is to consider how theories of individual testimony address the parallel question of whether acquiring testimonial knowledge from an individual speaker's testimony requires reference to the speaker knowing. Both 'eliminativist' and 'non-eliminativist' positions have been argued for. For example, Lackey (2008) argues that what explains an audience A's knowing that $\mathrm{p}$ on the basis of a speaker $\mathrm{S}^{\prime}$ s testimony to $\mathrm{p}$ are facts about the reliability of the speaker's testimony. Insofar as S's knowing that $p$ neither entails the reliability of S's testimony, nor is entailed by the reliability of $S^{\prime}$ s testimony, whether $S$ knows that $p$ is immaterial and this position is 'eliminativist'. Conversely, Burge (1993) proposes a 'non-eliminativist' position: in acquiring the belief that $p$ through understanding $S^{\prime}$ 's testimony to $p$, $A^{\prime}$ s belief that $p$ gets to be supported by whatever warrant $S$ possesses for believing that $p$. Understanding functions to transmit warrant between speaker and audience much as memory functions to preserve warrant from one time to another. Or consider Moran's (2005) proposal that in telling A that p, S offers A his assurance that $\mathrm{p}$. An assurance can be properly offered - and the responsibilities assumed in it discharged - only if $S$ knows that $p$ or justifiably believes that $\mathrm{p}$. So the explanation of A's getting to testimonially know that $\mathrm{p}$ must again refer to $S^{\prime}$ s knowing that $p$, and the explanation is 'non-eliminativist'.

These theories of individual testimony can then be applied, with little modification, to the case of collective testimony. So applied the resulting epistemologies of collective testimony have been labelled deflationary, non-reductive, and assurance respectively. This paper will consider these theories in reverse order in Sections 3, 4 and 5. It starts, in Section 1, with a couple of examples of collective testimony. In Section 2, it then develops an influential argument, which proposes that such examples offer grounds for recognising collective knowers. This argument for non-eliminativism then structures the presentation of the three theories of collective testimony. The position I will argue for in Section 6 is that one can recognise collective knowledge without recognising any collective knower. In denying the explanatory need for reference to a collective knower, this position is eliminativist. However, in giving an explanatory central place to collective knowledge, it develops a non-reductive position. ${ }^{5}$

4. Lackey (2014) uses the labels 'inflationary' and 'deflationary' for these positions.

5. For the resulting full table of positions, see the conclusion. 


\section{Collective Testimony}

It would be helpful to have a couple of cases of collective testimony to work with. I refer to two familiar cases. The first is Edwin Hutchins's (1995) description of navigation aboard the USS Palau before GPS technology. At the time of Hutchins's observations, a group of eight men formed the Navigation Department and were responsible for piloting the ship into port. To do this the bearing of the ship with respect to three known landmarks and a depth measurement had to be taken. These measurements would be taken every three minutes on a port approach and involved the operation of the whole team; for instance, the bearing recorder consults the maps, chooses the landmarks, and communicates these to the pelorus operators on deck, who then take the necessary bearings. The plotter then marks these lines of position on the map, fixes the boat's position and checks its correctness by comparing the chart depth with that recorded by the fathom operator. Communication with the engine room then allows the ship's future position to be reckoned, and on this basis the bearing recorder judges the next set of landmarks and the fix cycle repeats. Thus when the Head of Navigation tells the Captain that $\mathrm{p}$-that the ship is at such and such location proceeding North North West at 12 knots-he speaks for the Navigation Department who establishes this fact. Call this the navigation case.

The second case is Jon Hardwig's (1985) description of an experiment to record charm events and measure the life-span of charm particles which took ninety-nine physicists for its conduct. ${ }^{6}$ Such an immense collaboration was required because specific equipment needed to be built, Stanford's Linear Accelerator needed to be modified, and vast quantities of data needed to be analysed, a task requiring two hundred and eighty man years and a variety of expertise. Thus when the resulting paper in Physical Review Letters declares that $\mathrm{p}$ - that the charm cross-section is calculated to be such and such-this piece of testimony comes from the research team as a whole who established this fact and who are individually credited in the author list. Call this the physics case.

\section{From Collective Testimony to a Collective Knower}

The collective testimony given in the navigation case and physics case can ground testimonial knowledge. This fact, Hardwig claims, generates a dilemma: either we must say "that someone can know 'vicariously' -i.e. without possessing the evidence for the truth of what he knows", or we must allow that the experimen-

6. Knorr-Cetina (1999: 20) observes that the trend in high-energy physics experiments is towards greater collaboration; she cites the ATLAS experiment at CERN with approximately 2,000 collaborators. 
tal result "is known, not by any one person, but by the community" (1985: 348349). Faced with this dilemma, Hardwig suggests that the latter course is "more epistemologically palatable; for it enables us to save the old and important idea that knowing a proposition requires understanding the proposition and possessing the relevant evidence for its truth" (1985: 349). So he concludes that once we recognise that we can acquire testimonial knowledge from collective testimony, we must recognise that a collective can equally be a knowing subject. It follows that the epistemology of collective testimony should be non-eliminativist.

Hardwig's dilemma, I have suggested (Faulkner 2006: 171), can be presented as follows.

1. One can acquire knowledge that $p$ from collective testimony to $p$

2. Either this knowledge is testimonial or not.

3. If this knowledge is testimonial, then the speaker must have nontestimonial knowledge that $\mathrm{p}$.

4. The possession of non-testimonial knowledge that $\mathrm{p}$ requires the believing subject be able to articulate the appropriate grounds for knowing $\mathrm{p}$.

5. No one could articulate the grounds on which that $p$ is known.

6. Premises 1 to 5 are inconsistent.

The inconsistency of these premises should be clear. A reader of the Physical Review Letters, or the Captain of the USS Palau, testimonially knows that p. From premises 1, 2 and 3, this requires the speaker (the author of the Physical Review Letters or the Head of Navigation) know that $\mathrm{p}$ on non-testimonial grounds. But from premises 4 and 5 , no one possesses these grounds. It follows that $p$ is unknowable, contrary to the starting premise 1. Hardwig's dilemma then follows from considering which of this inconsistent set of premises can be rejected. Clearly, we take ourselves to possess scientific knowledge, and premise 1 is just an instance of this - that instance described in the physics case. Alternatively: clearly, we can navigate, and so know where we are and where we are going, and premise 1 is just an instance of this - that instance described in the navigation case. Either way, the possession of this knowledge, in the cases described, requires certain grounds, which is premise 4 . And premise 2 is a tautology. So the premises that are open to rejection are 3 and 5: either premise 3 is falseknowledge can be purely vicarious - or premise 5 is false-'someone' can articulate the needed grounds, to wit: the community.

The obvious worry with Hardwig's strategy is voiced by Lackey's (2014: 71) criticism of this general form of argument: as it stands, premise 3 has been shown to be false in the epistemology of individual testimony. Thus, Lackey (1999) gives a series of examples that tell against premise 3. One of these examples is that of a creationist teacher who tells her students, as the curriculum 
demands, a proposition to do with evolution, which she rejects. Her students get to know this proposition of evolution, but since the teacher does not believe it, she does not know it and premise 3 is false.

However, this case, and Lackey's other cases, merely show that the transmission of knowledge down a chain (from the evolutionary scientists to the students) can skip a link (the teacher). ${ }^{7}$ As such, premise 3 would be better formulated as:

$\left(3^{*}\right)$ If this knowledge is testimonial, then someone in the prior testimonial chain must have non-testimonial knowledge that $p .{ }^{8}$

A case against $\left(3^{*}\right)$ is then presented by Graham (2006): another creationist teacher discovers a fossil on a school field trip, correctly infers a new proposition in evolutionary theory, and tells this to his students. In this case, the teacher does not know this new proposition, because he does not believe it, but nor does anyone else in the prior chain of sources because it is a new proposal based on the teacher's observation of the discovered fossil. Nevertheless, it seems that the students can get to know this new proposition, so $\left(3^{*}\right)$ is false.

What is interesting about this fossil case is that it is similar to the navigation and physics cases; it is a case of what Hutchins (1995) would call "distributed cognition". To see this, consider a variation navigation case where the plotter has a peculiar paranoia: he believes all depth measurements are wrong. Provided the plotter proceeds in the way described-using the bearings given by the pelorus operators to plot the ship's position and confirming it against the charts with the fathom operator's depth measurement-his testimony that the ship is in suchand-such a position will allow the Head of Navigation to know this fact. That he is paranoid is immaterial. Equally, the teacher's creationism is immaterial. What matters is that, like the plotter, the teacher correctly combines two bits of knowledge-what he observes about the fossil and what he knows about evolutionary theory -in coming up with the new proposition. Now one must be careful in stating what the teacher knows about the fossil. He knows that it has this shape and look, etc. He knows that if it has this shape and look, etc., then evolutionary theory would propose that it is a fossil of X. And he correctly reasons, one might suppose, that if it is a fossil of $X$, then the new proposition of evolution follows. But he doesn't know either this new proposition or that it is a fossil of $X$ because he believes that evolutionary theory is false. Nevertheless, in knowing that the fossil has this look and shape, etc. and making the correct inferences, his testimony to the new proposition of evolution would allow his students to get to know it for the same reason that the testimony of the paranoid plotter

7. I discuss Lackey's cases further in Faulkner (2011: 71-75). See also Wright (2016).

8. Indeed $\left(3^{*}\right)$ was always the proposal. See Faulkner (2000: 595) and Burge (2013: 256). The reconstruction of Hardwig's argument I gave in Faulkner (2006: 171) uses $\left(3^{*}\right)$. 
would allow the Head of Navigation to know that the ship is at such-and-such position. Each correctly combines sources of knowledge to yield the new item of knowledge. From the epistemic position of the students or Head of Navigation, this knowledge, Burge says, then "resides, collectively, in the antecedent chain" (2013: 257). As such, $\left(3^{*}\right)$ would be better formulated as:

$\left(3^{* *}\right)$ If this knowledge is testimonial, then either someone in the prior testimonial chain or the chain taken collectively must have non-testimonial knowledge that $\mathrm{p}$.

The truth of $\left(3^{* *}\right)$ is necessary to support the intuition that the students acquire knowledge. For suppose that either evolutionary theory was not known by anyone, or that the teacher did not know what he observes about the fossil: if this supposition were true, there would be no temptation to conclude that the students nevertheless acquire knowledge of the new proposition of evolutionary theory.

If Hardwig's argument is then reconstructed with $\left(3^{* *}\right)$ rather than (3), Hardwig's attempt to preserve consistency by denying (5) is more compelling. Since $\left(3^{* *}\right)$ introduces the idea of the testimonial chain taken collectively, it is a small step to deny (5) by asserting that 'someone' could articulate the needed grounds for knowledge, to wit: the chain taken collectively could do so. Thus, it seems that once we recognise certain kinds of collective testimony, like the physics and navigation cases, and allow that we can acquire testimonial knowledge from these cases then either we need to allow 'vicarious knowledge' (that is, knowledge without the necessary knowledge-supporting grounds) or we must allow collective knowers. Hardwig proposes the latter horn of the dilemma; and in the next two sections I consider two non-eliminativist theories that develop this proposal. I will reject both.

\section{The Assurance Theory of Collective Testimony}

According to the assurance theory of individual testimony, what makes testimonial knowledge unique is that the explanation of its acquisition must refer to the testimonial relationship formed by the paired acts of a speaker telling an audience something and the audience believing the speaker. The key feature of telling is that it is something like a promise that what is told is true: in telling A that $p, S$ doesn't merely assert that $\mathrm{p}$ but additionally assumes responsibility for A's coming to believe truly that $\mathrm{p}$. The paired response is for $\mathrm{A}$ to believe that $\mathrm{p}$ is true because A believes $S$, or trusts $S$ for the truth. Insofar as this relation exists, when $\mathrm{S}$ then knows that $\mathrm{p}$, and so can discharge the responsibility she assumes, A gets to know that $p$ through trusting $S$ for the truth as to whether $p$. 
Evidence for this assurance explanation of our acquisition of knowledge from individual testimony then comes from the reactive attitudes we demonstrate as speakers and audiences. Were A to not believe $S$, or to merely believe what $S$ says, rejecting $S^{\prime}$ s assumption of responsibility, $S$ would be liable to feel affronted. And were S's telling a lie or S's telling not adequately grounded in the truth, A would feel that his trust had been betrayed. These reactive attitudes, Miranda Fricker (2012) then observes, are equally found in the case of collective testimony. She imagines the case of a committee tasked with producing a report into the health risks associated with commonly used food additives. This report is well-publicised and a citizen, A, reads and believes it. Subsequently, it then transpires that the food companies, whose practices were under scrutiny, had influenced the committee.

Our citizen is betrayed. He trusted the committee's word, but they abused his trust, and doubtless that of many other members of the public. All the defining trust related features of testimony are present in this case. (Fricker 2012: 273)

That A would feel betrayed indicates one side of the testimonial relation, namely that A trusted the committee for the truth on this matter. In doing so, A would take the report as an assumption of responsibility, or as Fricker puts it as a "commitment to second personal trustworthiness concerning whether p" (2012: 271) - that is, concerning whether, and in what ways, commonly used food additives pose a risk to health.

The other side of the testimonial relation is that $\mathrm{S}$, the committee, did in fact assume this responsibility or make this commitment to trustworthiness. And it is possible for a committee to undertake this commitment, Fricker argues, insofar as the committee, as a social group, is constituted by various joint commitments. That social groups are so constituted in this way is Margaret Gilbert's (1989) influential proposal. According to Gilbert, the most rudimentary social groups, are formed when people do things together-have a picnic together, do an experiment together, pilot a boat together and so on-and doing things together is just a matter of jointly committing to that course of action. Joint commitment is then a basic notion, which defines and identifies collectives. ${ }^{9}$ Fricker's proposal follows:

My proposal is that we construe a group testifier as constituted, at least in part, by way of a joint commitment to trustworthiness as to whether $p$ (or

9. Thus, collective intentions can be defined in terms of it: "A and B collectively intend to do $X$ if and only if A and B are joint committed to intend as a body to do X" (Gilbert 2003: 49). Compare List and Pettit (2011: 33). 
whatever range of p-like questions might delineate the body's expertise, formal remit, or informal range of responsibility). (2012: 272)

She adds, "I suspect that any collective body whose role is likely to involve telling people things would need to have this as one of its constitutive commitments" (Fricker 2012: 272). But the main thesis is the weaker: where a collective has a joint commitment to trustworthiness it is capable of entering "into the secondpersonal relations of trust that characterize testimony" (Fricker 2012:272). When this is so and its receipt is trusting, it is possible to give an assurance explanation of our acquisition of knowledge from collective testimony.

The problem with this assurance theory of collective testimony is one of scope; otherwise put, it fails of sufficiency: there are cases where we acquire knowledge from collective testimony that cannot be accounted for in assurance terms. ${ }^{10}$ While we can have the kind of testimonial relation to a collective testifier that supports the described set of second-personal attitudes and emotions, this is not ordinarily the case. A key feature of the testimonial relation, which is the central focus of the assurance theory of individual testimony, is that it is a person-specific relation involving attitudes towards and about another specific party. In trusting $S$ for the truth, A expects something of $S$, which is that $S$ will be moved by his, A's, need for the truth. ${ }^{11}$ Fulfilling this expectation, and being trustworthy, then requires that $S$ act for this reason; mere reliability would not be enough to satisfy this expectation, nor would it be enough for trustworthiness. To use Baier's (1986: 235) example: Kant's regularity of habit allowed his neighbours to tell the time from his walks, but his neighbour's need to know the time was no part of his reason for walking, so there is no trust to betray and, as Fricker (2012: 256) acknowledges, no "second personal" trustworthiness. Equally, in being moved by $A^{\prime}$ 's need to know whether $\mathrm{p}$, in being "second personally trustworthy", $S$ takes responsibility for $A$ 's coming to believe that $\mathrm{p}$, and only for A's belief. Thus, the assurance theory identifies a difference in epistemic position between one who is told and one who merely overhears, and that there is such a difference is often taken to be evidence for the assurance explanation. ${ }^{12}$

In the case of collective testimony, it is possible for such a person-specific relationship to exist. This is plausibly true of the navigation case. When the Head of the Navigation Team tells the Captain that $\mathrm{p}$ - that the ship is at such and such location proceeding North North West at 12 knots - the Head of Navigation is speaking for the Navigation Team that responds specifically to the Captain's

10. This is the criticism I make of assurance theories of individual testimony, see Faulkner (2011: 167-169).

11. See Faulkner (2007) and Jones (1996).

12. See, in particular, Hinchman (2005). 
need for this information. And when he tells the Captain this, the Head of Navigation specifically assumes responsibility for the Captain's belief that $p$.

However, this case is unusual in this respect, and our relation to collective testimony is not generally like this. It is not true of the physics case, for instance. The reason for the article in Physical Review Letters is to accurately describe the experiment and publicise its result. It is to contribute to science. It is not addressed to any audience in particular. Equally, the reason for the committee report is not citizen $A^{\prime}$ 's specific need for information as to the health risks of food additives, and the committee report is not addressed specifically to $A$. It follows that citizen A's receipt of this report would not, contrary to Fricker (2012: 272), instantiate "the defining trust related features of testimony", and that Fricker's description of A's reactive attitudes is mistaken. While the Captain might feel betrayed by the Navigation Team, if, say, it turns out they haven't been following procedure and his ship runs aground, citizen $A$ is not going to feel this distinctive reactive attitude. No doubt A might feel that a wrong has been done, feel indignant at the corruption and disappointed about being misled. There is the moral emotion of resentment here. But there is not the distinctive emotion of betrayal because that would require that A feel personally wronged by the falsehoods published.

In Fricker's defence, she notes that we do not always treat collectives as good informants, to whom we can stand in these second-personal trust relations, but sometimes take them merely to be 'sources of information' - a little like Kant's neighbours might take his walks as a source of information. ${ }^{13}$ However, the objection is not that we do not always treat collectives as good informants, but that our doing so is the exceptional case. We rarely have a person-specific relation to a bit of collective testimony, but ordinarily confront it anonymously as the committee report, scientific article and so on.

\section{The Non-Reductive Theory of Collective Testimony}

According to non-reductive theories of individual testimony, what makes testimonial knowledge unique is that it is transmitted knowledge. With this the assurance theory would agree: knowledge is transmitted one-way as epistemic responsibility is transmitted the other. What differentiates the non-reductive theory is then the explanation of transmission given. ${ }^{14}$ The general idea is that it

13. 'A little' because Kant's walk would be a 'passive' source of information whereas testimony is an 'active' source-at least all the while the belief formed is its content. See Fricker (2012: 273, 251) for this distinction.

14. That and the claim that we have a general entitlement to accept testimony, which is something the assurance theory would reject. 
is the basic function of language to communicate knowledge. Thus, an audience A can get to know that $p$ on the basis of $S^{\prime}$ s testimony to $p$ just because $S$ knows that $\mathrm{p}$ and successfully communicates this knowledge to A. Evidence for this explanation then comes from consideration of the nature of language and thought. Thus, and for instance, Burge (1993) gives a complex apriori account that starts from our capacity to understand language. ${ }^{15}$ It is this capacity for understanding that determines that our communication is grounded in what Burge (1993: 467) calls the acceptance principle, or an entitlement to accept what is (seemingly) intelligibly presented as true. (Call such presentations 'testimony'.) And it is this capacity for understanding that means that "in communication, perception plays a connecting and preservative role analogous to the role memory plays in deductive reasoning" (Burge 1997: 24). That is, it "simply maintains in justificational space a cognitive content with its judgemental force" (Burge 1993: 465).

Thus, in a simple case, through understanding and believing S's testimony to $p$, an audience $A$ acquires a belief that inherits whatever warrant $S$ has for this belief. The relevant warrant here is what Burge (1993: 486) calls the "extended body of justification" rather than the audience's "own proprietary justification". The latter will be composed of that entitlement stated by the acceptance principle together with any independent reason that A has for believing that $\mathrm{p}$, including any empirical reason for believing that $S^{\prime}$ s testimony to $p$ is credible. The former is this plus what is inherited with testimonial uptake. What distinguishes testimonial knowledge is that it knowledge based on this extended body of justification.

If the recipient depends on interlocution for knowledge, the recipient's knowledge depends on the source's having knowledge as well.... The recipient's own proprietary entitlement to rely on interlocution is insufficient by itself to underwrite the knowledge. . . . [It] is incomplete and implicitly refers back, anaphorically, to fuller justification or entitlement. ... [It is this] the extended body of justification that underwrites the recipient's knowledge. (Burge 1993: 486)

No doubt Burge would allow that an audience A's proprietary justification - an argument to the credibility of S's testimony to $p$, say-could be sufficient for inductive knowledge. The point is that testimonial knowledge is knowledge that is based on an extended body of justification. So for A to testimonially know that $p$ on the basis of $S$ 's testimony to $p$, the extended body of justification inherited from $S$ needs to be knowledge supporting, which is to say that "there must be knowledge in the chain" (Burge 1993: 486, Footnote 24).

15. I discuss Burge's theory of testimony in Faulkner (2000) and Faulkner (2011). 
Thus, is his Postscript to Content Preservation, Burge clarifies that the condition on acquiring testimonial knowledge is that

(A) knowledge must reside in the chain of communicators that leads up to a report, if the recipient is to obtain knowledge from the report. (2013: 255)

This is equivalent to premise $\left(3^{* *}\right)$ in the reconstruction of Hardwig's (1985) argument given in Section 2, and Burge's non-reductive theory of individual testimony naturally extends to give a theory of collective testimony. On this extension, when $\mathrm{A}$ is the recipient of collective testimony to $\mathrm{p}$, A gets to testimonially know that $p$, or gets to be testimonially justified in believing that $p$, simply because the collective knows or is justified in belief, and A understands and believes the collective testimonial expression of this knowledge or justified belief. Provided A has no reason to believe that not-p, defeating the entitlement stated by the acceptance principle, nothing more is needed to explain A's testimonially knowing that $\mathrm{p}$, on the basis of collective testimony to $\mathrm{p}$ than that the collective knows that $p$.

An advantage of this non-reductive explanation over the assurance explanation is that it is less ontologically committed. Both are committed to the claim that collectives can be knowing subjects. But the assurance explanation is further committed to the claim that collectives are minimally constituted by a joint commitment to trustworthiness, where this requires, according to Gilbert, that this commitment be "openly expressed" and "common knowledge" (2003: 53). In addition, I argued in Section 3, the assurance explanation is further committed to the idea that the collective testifier stands in a person-specific relation to the audience. The non-reductive theory need endorse neither of these commitments. Nevertheless, it can preserve the idea of collective knowers, Alexander Bird suggests, by appeal to a distributed model of group identity, where group identity comes not from joint commitments but from "mutual dependence arising from, above all, the division of labour" (2014: 54). On this model, "the fact that certain people have mutually interacting jobs or roles may be sufficient to bind them together" (Bird 2014: 59). This model applies naturally to the navigation and physics cases because each involves a division of epistemic labour organised around an epistemic goal. This offers a basis for speaking of the collective knowing; and similarly, one might refer to the 'project' or 'program' knowing as in "the Manhattan project discovered how to harness the power of nuclear fission" (Bird 2014: 59). It follows that in all these cases, a collective version of the nonreductive explanation can still be applied. In the physics case, for example, the reader of the Physical Review Letters gets to be justified in believing that $\mathrm{p}$ because this is what the research group is justified in believing. 
However, the non-reductive theory of collective testimony, like the assurance theory of collective testimony, is inadequate in its scope of explanation; otherwise put, it equally fails of sufficiency: there are cases where we acquire knowledge from collective testimony that cannot be accounted for in terms of the collective knowing and this knowledge getting transmitted. First, the suggested principle of collective identity will not cover all cases of collective testimony. Thus, consider the loose collective formed by Graham's (2006) creationist teacher and the prior evolutionary scientists this teacher learnt from. There are no joint commitments defining this collective, and specifically there is no joint commitment to trustworthiness since one cannot demonstrate this commitment in testifying to what one believes is false. But equally there is no mutual dependence arising from a division of labour. The collective, insofar as it exists, is identified only by this specific testimonial chain.

Second, consider the case of the dead scientist. Dr. $\mathrm{N}$ discovers that $\mathrm{p}$ and publishes his discovery in the Journal of X-ology. This publication is ignored and Dr. $\mathrm{N}$, along with the scientists who peer reviewed the paper, subsequently pass away. As such, there is no individual, or set of individuals, who either know that $\mathrm{p}$ or believe that $\mathrm{p}$. Nevertheless, Bird contends,

Dr. N's contribution to knowledge did not cease with his death. Rather his discovery is a contribution to what is known in wider science in virtue of its publication and remains known thanks to the accessibility of that publication. . . . For the system to know something, what is in people's heads is not important; what is important is the availability of the information known. (2014: 57)

This description of the case, I think, is wrong. If there is no member of the collective that knows that $\mathrm{p}$, it is wrong to say that the collective - or "the system" knows that $\mathrm{p}$. There is collective knowledge. And there is collective knowledge for the reason that Bird describes, namely that the knowledge supporting justification printed in the Journal of X-ology is still available. But there is no collective epistemic subject and so no collective knower. If this is the case, suppose that an audience A reads Dr.N's article in the Journal of X-ology. On the basis of this testimonial encounter, A could get to testimonially know that $p$. But if there is no collective knower, this fact cannot be explained in terms of the collective knowing that $\mathrm{p}$. Thus, the non-reductive theory of collective testimony fails for cases like this.

The case of the dead scientist, I propose, rather suggests a simpler eliminative hypothesis: what explains A's getting to testimonially know that $\mathrm{p}$ on reading Dr.N's article is just the epistemic credentials of this bit of testimony. In the next two sections, I consider two ways of elaborating this eliminative hypothesis. 


\section{The Deflationary Theory of Collective Testimony}

In considering the epistemology of collective testimony, Jennifer Lackey (2014) proposes an eliminativist, or in her terms, a deflationary account. One can explain the knowledge and justified belief we acquire from collective testimony without any reference to a collective knowing or being justified in belief. ${ }^{16}$ No such reference is needed because the focus should rather lie on the reliability of testimony. Thus, what motivates Lackey's (2014) deflationary position is her statement view in the epistemology of individual testimony (SVT).

SVT: For every speaker, S, and hearer, H, H knows that $\mathrm{p}$ on the basis of $S^{\prime}$ s testimony only if (I) S's statement is reliable or otherwise truthconducive, (2) $\mathrm{H}$ understands that $\mathrm{p}$ and comes to truly believe that $\mathrm{p}$ on the basis of the content of $\mathrm{S}^{\prime}$ s statement, and (3) H has no undefeated defeaters for believing that $p$. (Lackey 2014: 78)

What then needs to be added to these necessary conditions to generate an explanation of H's acquisition of knowledge from S's testimony to p? Obviously, (4) that $\mathrm{p}$ is true. And a fuller statement of the statement view also adds: (5) H has positive reasons to believe S's testimony to $\mathrm{p}$, where these "render it, at the very least, not irrational for $[H]$ to accept [S's] testimony" (Lackey 2008: 181). ${ }^{17}$ That we can have such positive reasons, and that our collective testimonial beliefs should be based on them, is then something that has been argued by Tollefsen (2007). We form generalizations about the credibility of collectives, Tollefsen (2007: 306308) notes, just as we form generalisations about the credibility of individual testifiers. And in both cases, we bring our background knowledge to bear in assessing testimony.

In short, what matters is testimonial reliability and some judgement of this. This view is then eliminative since neither of these requirements need involve any essential reference to the collective knowing or being justified in belief. This is particularly so, as Lackey observes, given that collective testimony itself can be delivered by a spokesperson. ${ }^{18}$ For instance, it is the Head of Navigation that tells the Captain that $\mathrm{p}$ in the navigation case; and it is the person who wrote the multiple authored the publication in Physical Review Letters who tells the readers

16. See also Tollefsen (2007).

17. For criticism that in failing to specify sufficient conditions, Lackey fails to specify an account of when testimonial beliefs are justified, see Faulkner (2013).

18. Where, as Lackey notes, a spokesperson doesn't need to be a member of the group they speak for. See also Ludwig (2014). It should be noted, however, that not all collective testimony will have a spokesperson: a collectively edited Wikipedia page does not, see Tollefsen (2009). And see next note. 
that $\mathrm{p}$ in the physics case. ${ }^{19}$ Lackey (2014:68) uses the example of a report charting the progress of populations, issued by the U.N. Population Commission, which comprises forty-seven individual members. Someone will have authored this report (Lackey calls that person 'Sam') so while the report is the collective testimony of the U.N. Population Commission, it is delivered by spokesperson Sam. (Call this the commission case.) It is thereby Sam who reports that $\mathrm{p}$-that the birth rate of Latinos in the U.S. is on the rise-and it is the reliability of Sam's testimony, and the reasonableness of accepting Sam's testimony that matter. Thus, a reader will get to know that $p$ if and only if conditions (1) to (5) above are satisfied. None of these conditions need refer to the collective knowing or being justified in belief.

With respect to Hardwig's (1985) argument, presented in Section 2, this position embraces the first horn of the dilemma: we can know things 'vicariously'; that is, it is not the case that our possession of testimonial knowledge entails that someone can articulate the appropriate (non-testimonial) grounds for our knowledge. This is not the case because testimonial knowledge is grounded fundamentally on the reliability of the testimony it is based on. Now it might be agreed that the reliability of testimony will suffice to explain our acquisition of testimonial knowledge on many occasions. Specifically, it will be sufficient when knowledge of the testimonially believed fact is the kind of knowledge that can be sustained on the basis of reliability. For example, arguably we know what we see to be so because of the reliability of vision. If this is so, and a speaker sees that $\mathrm{p}$ and tells an audience $\mathrm{A}$ that $\mathrm{p}$, then what explains A's getting to know that $\mathrm{p}$ will be facts about the reliability of the process operative in A's coming to believe that $\mathrm{p}$. And this could be equated with the reliability of the testimony, as Lackey (2008) proposes. ${ }^{20}$ Moreover, there could be cases of collective testimony where the same is true-for example, where a group of independent witnesses help a crime scene investigator piece together what happened - so there will be cases where Lackey's (2014) deflationism is explanatorily adequate. The problem, as with the assurance and non-reductive theories of collective testimony is then one of explanatory scope; again, otherwise put, it equally fails of sufficiency: there are cases where we acquire knowledge from collective testimony and it is an explanatory failure to stop at the level of testimonial reliability. In these cases, the explanation of our acquiring knowledge from collective testimony requires digging deeper than reliability to those facts that determine this reliability and explain the possibility of this knowledge.

The physics case used by Hardwig (1985) to introduce his argument is one

19. Assuming, that is, there is a single author, which there need not be. See Kukla (2012) for an account of authorship in radically collaborative papers.

20. Other reliabilist theories don't make this equation; for instance Goldberg (2010) focuses on the extended process that would include the speaker's vision. 
such case, as too is the navigation case. The Head of Navigation is the spokesperson for the Navigation Team, and his testimony to the ship's position reliably indicates this position. But any explanation of why it is that the Captain gets to know that $\mathrm{p}$-that the ship is in such and such a position-on the basis of the Head of Navigation's telling him that $\mathrm{p}$ should not stop at the fact that this piece of testimony is reliable. Rather, explanation should continue and refer to the calculations that support this knowledge.

Or consider Lackey's commission case. And consider first what cognitive work spokesperson Sam does. According to Lackey, Sam "interprets and compiles all of the data contributed by members of [the U.N. Population Commision] into the published report" (2014: 78). This sounds like a substantial contributionsimilar to the kind of contribution Graham's (2006) creationist teacher makes in proposing a new proposition of evolutionary theory - so the question is, does Sam know that $\mathrm{p}$ on the basis of testimony? That is, is that $\mathrm{p}$ a fact Sam simply transcribes in her report? Or does Sam infer that $p$ in making the report and so know that $\mathrm{p}$ by inference from other facts (themselves known through testimony)? In the latter case Sam makes a cognitive contribution since the knowledge that $\mathrm{p}$ begins with her. Thus, if Sam is to be merely a spokesperson and merely "speak for the group", the case must fit the former description: Sam must do no more than simply transcribe the facts that she reports. However, if this is the case, reference to the reliability of Sam's statement, along with a reader's judgement of it, is arguably not sufficient to explain how it is that the reader of the U.N. Population Commission's report gets to know that $\mathrm{p}$ - that the birth rate of Latinos is on the rise in the U.S. Rather, the explanation needs to go further and refer to the data supporting that $\mathrm{p}$-that is, the relevant statistical data-and claim that this data is knowledge supporting.

To pursue this argument further consider the Eddington case as developed by Boaz Miller (2015). Einstein's theory of General Relativity implies that massive bodies like the Sun will deflect light and this deflection, Eddington proposed, could be observed in a change in the position of the stars during a total solar eclipse. So in 1918 he organised two expeditions, to West Africa and Brazil, to provide the needed photographic evidence. Following these experiments, in 1919, the Royal Society and New York Times declared General Relativity confirmed. In fact, Eddington had discarded eighteen photographic plates whose inclusion would have shown the experiment to have disconfirmed General Relativity; and, short of a reason for discarding the slides, Eddington was not justified in claiming otherwise. ${ }^{21}$ Following Miller (2015: 423) two cases can then be imagined. (1) Things are as they were and the testimony in the New York Times reports a successful result, when there wasn't one. (2) The New York Times

21. For detail on this bit of history, see Earman and Glymour (1980).

Ergo • vol. 5, no. $4 \cdot 2018$ 
reports the experiment in the same terms, but the experiment was actually the success it was reported to be. On the assumption that General Relativity is true, there is no difference in the reliability of the report in the New York Times in these two cases, (nor need there be any difference in the rationality of a lay audience's belief in the two cases). Thus, according to the deflationary model there would be no difference in the knowledge or justification-put generally, no difference in the epistemic standing - of the lay audience's testimonial belief across these two cases. This lack of difference implies that the scrupulousness that Eddington counter-factually demonstrated in case (2) - or conversely the bias and that he demonstrated in case (1)-makes no epistemic difference to the epistemic standing of a lay audience's testimonial belief in these two case. But this seems wrong. ${ }^{22}$

This brings a return to Hardwig's (1985) argument. As presented, Hardwig's argument is that collective testimony presents a dilemma: either we allow that an individual knows 'vicariously'; or we must allow collectives who know 'nonvicariously' - that is, who possess the needed body of evidence. The cases which show the limitation of the deflationary view suggest that what motivates this dilemma is the idea that there are certain requirements on knowing certain facts (where this is implicit in the qualifier 'appropriate' in premise (4) of the argument as reconstructed in Section 2). In the physics case, knowing, or being justified in believing, that the charm cross-section is such-and-such requires doing the experiment described in the Physical Review Letters. Empirical confirmation of General Relativity requires a successful experiment, not a fudged one. Knowing that the birth-rate of Latinos is on the rise in the U.S. requires a body of statistical data. And knowing one's nautical location, prior to the invention of GPS technology, requires that certain measurements be taken and calculations made. It may be that some propositions can be known on the basis of reliability - known without evidence or proof, known 'vicariously' as Hardwig says-but these propositions cannot.

It follows that what best motivates non-eliminativism in the epistemology of collective testimony are cases of knowledge where: (i) a specific kind of evidence or argument is needed for knowledge; and (ii) this evidence or argument can only be generated at a collective level. Call cases that satisfy these conditions core cases. It is with respect to core cases that the deflationary account is an explanatory failure. Moreover, a non-eliminativist would add that these cases can be explained satisfactorily by appeal to a knowledgeable collective. For instance, in the Eddington case the difference between cases (1) and (2) tracks a difference in

22. Or consider the case of Fermat's Last Theorem under the supposition that Fermat did in fact prove it. And then compare the cases of a lay audience who hears of the theorem indirectly (i) when Fermat is still alive and (ii) after his death (but before Andrew Wiles's recent proof). See Faulkner (2000: 597-598). 
what Eddington, and the scientific community, knows. However, Sections 3 and 4 have considered two non-eliminativist theories and found both wanting. So in the next section I consider a different way of pursuing the idea that what matters is the epistemic credentials of a piece of collective testimony. Lackey's deflationism elaborated this in terms of testimonial reliability, the next section elaborates it in terms of collective knowledge, where the starting idea is that there can be collective knowledge without a collective knower.

\section{Collective Knowledge without a Collective Knower}

First the proposal. According to the non-reductive theory of collective testimony outlined in Section 4, testimonial knowledge is identified as transmitted knowledge. In the paradigmatic case, Burge observes that "If the recipient depends on interlocution for knowledge, the recipient's knowledge depends on the source's having knowledge as well" (1993: 486). This is true whether the source is an individual or a collective. The body of justification that includes the source's proprietary justifications and entitlements, Burge calls the extended body of justification, where it is the source's contribution to this that is preserved across the testimonial link. The present proposal is then that this extended body of justification can be considered in abstract; that is, considered independently of whether there is any source belief that it might support. It is not that justification gets transmitted from the source's belief-be that individual or collective - to the audience's belief but that testimonial uptake is a way in which an audience's belief gets to be supported by an extended body of justification. ${ }^{23}$

To illustrate this proposal, consider again the dead scientist case. Since Dr. N is dead there is no individual belief to consider; and since the referees are dead, so too the copy editor, and Dr. N's paper has been forgotten, there would seem to be no collective belief either. But Dr. N's result is still is supported by an appropriate knowledge-supporting body of extended justification-where this is the conjunction of the data and argument articulated in Dr. N.'s article in the Journal of X-ology together with whatever theory is needed to understand this publication. For this reason a reader of Dr. N's article in the Journal of X-ology would seem to be able to get to testimonially know that $\mathrm{p}$. The present proposal is that the reader can acquire this testimonial knowledge through reading Dr. N's article because that $\mathrm{p}$ is supported by a knowledge-supporting extended body of justification. ${ }^{24}$ Or, put more simply: the reader can come to know that $\mathrm{p}$ because

23. I present this theory in Faulkner (2000) and Faulkner (2006). See also Miller (2015).

24. This assumes that the reader's testimonial uptake is appropriate. For Burge being 'appropriate' requires merely that the reader has no reason to not believe $\mathrm{p}$. This is because we have the entitlement stated by his Acceptance Principle, which then refers "anaphorically" to the fuller jus- 
it is collective knowledge that $\mathrm{p}$. That this is collective knowledge does not require anyone-individual or collective - know that $\mathrm{p}$. What its being collective knowledge does require is ( 1 ) that $p$ be supported by an appropriate knowledgesupporting extended body of justification, which (2) the collective has access to. To develop this proposal further (1) and (2) need to be elaborated on. I will do this first and then consider how the resulting position relates to Burge's nonreductive theory and Hardwig's (1985) argument for non-eliminativism.

Condition (1): that $p$ be supported by an appropriate knowledge-supporting extended body of justification. The idea that a body of justification needs to be appropriate for knowledge of $\mathrm{p}$ was introduced in the last section, and I'll not say more about it now. It is the idea that knowledge of the charm cross-section requires the experiment, as does the empirical confirmation of General Relativity, etc. The other key component of condition (1) is the idea that the justification of a proposition can be considered independently of the justification of a belief. However, this distinction is in fact an epistemological common-place. For example, consider Ginet's case of adultery where a husband believes that his wife is having an affair on the testimony of a "notoriously untrustworthy gossip" (1975: 32). The right thing to say about this case, given that the husband has ample evidence of his wife's affair, is that his belief is unjustified, because it is based on gossip, but justifiable, given the evidence he has. This claim then distinguishes the justification of the husband's belief from the justification the husband has for the proposition believed. To focus on the justification of a proposition is then to consider the relation of this proposition to a body of justification abstract from the question of belief.

That epistemology should study the justification of propositions-focusing on the data and arguments that can be marshalled in their support-rather than the justification of belief is also Popper's (1972b) controversial contention. Thus, Popper draws a parallel distinction between subjective and objective conceptions of knowledge. To identify knowledge as a mental state-ordinarily belief-is to conceive of knowledge in the subjective sense. Talk of collectives knowing then extends this subjective conception: the collective is modelled as an individual knower. However, insofar as epistemology "aims at a theory of scientific knowledge" then, Popper (1972a: 108) argues, this subjective conception of knowledge "is irrelevant in a pretty strict sense of the word". Epistemology should rather concern itself with "the world of theories in themselves, and their logical relations; of arguments in themselves; and of problem situations in themselves" (Popper 1972c: 154). This should be the focus because although scientific knowl-

tification that is the extended body of justification. I have argued that being 'appropriate' requires that the audience have some positive reason to believe that $\mathrm{p}$, such as the reputation of the Journal of X-ology; see Faulkner (2000). However, as stated at the beginning of this paper this debate about what justifies our testimonial uptake is beyond the scope of this paper. 
edge is a human creation, it also possesses a degree of autonomy in its existence. This is illustrated by the fact that Dr.N's discovery does not cease to be knowledge with his death and the death of the referees. It remains as knowledge because of its publication. ${ }^{25}$

Now I do not want to defend Popper's conception of a "third world" of objective knowledge alongside the "first world" of facts and the "second world" of mental states, since it has come in for some trenchant criticism. ${ }^{26}$ Rather, I want to simply take Popper's distinction between the subjective and objective senses of knowledge to be parallel to the distinction between the justification of a belief and the justification of a proposition, and focus on this latter distinction. This distinction comes to the fore in the epistemology of collective testimony because in the core cases our epistemological interest lies, as Popper states, in the proposition - the location of the ship, the charm cross-section, the population growth, etc. - rather than whether this proposition is believed. ${ }^{27}$

Condition (2): that the collective has access to this extended body of justification. In core cases, working out whether $\mathrm{p}$, and so getting to know whether $\mathrm{p}$, requires a division of epistemic labour. Thus, and for instance, it takes the whole Navigation Team to work out where the ship is in the navigation case; and it takes the listed ninety-nine authors to work out the charm cross-section in the physics case. As such, articulating the knowledge-supporting justifications in these core cases is a collective effort. On the assumption that epistemic access requires knowledge of the justifying facts and knowledge that these facts justify, it follows that no individual alone has access to these knowledge-supporting justifications. However, on the same assumption the collective will have such access. In the dead scientist case, access is then satisfied by the conjunction of (i) the fact that Dr.N's article is available, since it is in the library, and (ii) the fact that the collective still has members that know the relevant theoretical background so that they would understand the article if they read it. This weakening of the access condition parallels that in individual epistemology where access is normally taken to be 'access on reflection', which means 'is available to consciousness' as opposed to 'is aware of', because it can take reflection to bring to consciousness the basis of some belief.

Toreturn now to Burge and Hardwig's(1985) argument for non-eliminativism.

25. And here Popper gives a similar case: he asks us to imagine two apocalyptic situations, in both our civilisation is destroyed but in the first case the libraries are preserved. The intuition is that "in the second case there will be no re-emergence of our civilisation for many millennia" (Popper 1972a: 107-108). And this is because the library books contain knowledge in the objective sense merely because of their "possibility or potentiality of being understood" (Popper 1972C: 115-116).

26. See Cohen (1980), Currie (1978) and $\mathrm{O}^{\prime}$ Hear (1980). I offer some defense in Faulkner (2006). See also Baird (2004: Chapter 6).

27. In talking about the knowledge contained in a library book, Popper observes "whether anybody ever reads it and really grasps its contents is almost accidental" (1972C: 115-116). 
"Knowledge", Burge (2013: 255) says, "must reside in the chain of communicators that leads up to a report if the recipient is to obtain knowledge from the report". As observed, the standard non-reductive position is to extrapolate the collective case from the individual case: knowledge and justification reside in the chain through being possessed either by some individual member of the chain, or the chain taken collectively. It is this individual or collective knowledge or justified belief that is transmitted. The present suggestion marks a departure from this view. It proposes that justification can be conceived independently of belief-conceived objectively as Popper would say. But it also seems that Burge is equally driven to this objective conception of justification when he considers a core case of collective testimony. Thus, in describing Graham's (2006) creationist teacher case, Burge says,

the knowledge the students acquire is the product of the knowledge of the teacher's sources, the teacher's own observational knowledge, and a good inferential step taken by the teacher. In an abstract sense, the knowledge that the students gain resides, collectively, in the antecedent chain, including the teacher (with his / her knowledge of the fossil). We do talk this way about complex scientific or mathematical work. (2013: 257)

This suggests that knowledge can reside in the chain even if there is no individual or collective knower; that what matters is just that there is collective knowledge, where this, I suggest, can be conceived abstractly as described above.

With respect Hardwig's (1985) argument, this argument starts from the fact that an individual can gain testimonial knowledge from a piece of collective testimony, and proposes that this generates a dilemma: either knowledge can be 'purely vicarious'; or someone possesses the needed knowledge supporting justification. With respect to the physics case that forms the basis of Hardwig's (1985) argument, knowledge cannot be 'purely vicarious': knowing that the charm cross-section is such-and-such requires a supporting body of evidence and argument. So one must embrace the other horn of the dilemma and conclude that 'someone' must possess this. Given the complexity of this extended body of justification, that 'someone' could only be the collective. However, if it is allowed that knowledge can be considered in abstract from the knowing subject, this dilemma is a false one. That is, it does not follow from the fact that knowing the charm cross-section requires an extended body of justification that someone must be able to articulate this body of justification. The articulation of this extended body of justification is a collective endeavour not the endeavour of the collective. (In terms of the reconstruction of Hardwig's argument given above in Section 2, the dilemma of either denying $\left(3^{* *}\right)$ or $(5)$ doesn't arise because it is (4) that is false.) 


\section{Conclusion}

What explains our learning that $\mathrm{p}$ from collective testimony to $\mathrm{p}$ ? This paper has argued that different answers to this question employ different degrees of collective commitment. This could be represented in tabular form.

\begin{tabular}{|l|l|l|}
\hline Theoretical Position & Eliminativist or not? & Collective notions employed \\
\hline Assurance & Non-eliminativist & $\begin{array}{l}\text { Collective knowledge \& belief } \\
\text { Collective knower \& believer } \\
\text { Collective subject }\end{array}$ \\
\hline Non-reductive & Non-eliminativist & $\begin{array}{l}\text { Collective knowledge \& belief } \\
\text { Collective knower \& believer }\end{array}$ \\
\hline This paper's position & Eliminativist & Collective knowledge \& belief \\
\hline Deflationary & Eliminativist & None. \\
\hline
\end{tabular}

Non-eliminativist answers to this question explain our learning that $\mathrm{p}$ by reference to the collective knowing that $\mathrm{p}$. This paper considered and rejected two non-eliminativist answers. First, it considered an assurance theory of collective testimony. What explains our learning that $p$ is the fact that there is some collective, which knows that $p$, and assumes responsibility for our coming to know that $p$, in the same way that an individual speaker can assume this responsibility. This theory failed of sufficiency: it does not cover cases of collective testimony where there is no assumption of responsibility for the audience's belief. Second, it considered the straight application of a non-reductive theory of individual testimony: what explains our learning that $p$ from collective testimony to $p$ is simply the fact that the collective knows that $\mathrm{p}$ : knowledge can get transmitted from the collective epistemic subject to an individual just as it can get transmitted from individual to individual. This theory equally failed of sufficiency: it does not cover cases of collective testimony where there is no collective knower.

The paper then moved on to consider an eliminativist theory of collective testimony. We can explain our learning that $p$ from collective testimony to $p$ without referring to any collective epistemic subject because all that matters is the reliability of the individual spokesperson who represents the collective and an audience's judgement of this reliability. This is the deflationary theory; again, it was argued that this proposal fails of sufficiency: many of the truths that are presented by collective testimony require more than reliability, and the judgement of it, to be known.

Having rejected these options, the paper presented an eliminativist interpretation of the non-reductive theory. This might be termed an objectivist-or even 
third-world-epistemology of collective testimony. What explains our learning that $\mathrm{p}$ from collective testimony to $\mathrm{p}$ is that this proposition is collective knowledge, or supported by an appropriate knowledge supporting body of extended justification that the collective has access to. Taking this option requires thinking of knowledge and justification independently of the epistemic subject who can know or be justified in belief. It follows that no reference to the collective knowing is needed to explain our acquiring testimonial knowledge from collective testimony. Hence this position is eliminativist. However, this does not entirely eliminate reference to the collective since this body of extended justification is possessed only conditionally upon its collective accessibility.

\section{Acknowledgments}

My thanks to a couple of anonymous referees and the copy editor.

\section{References}

Baier, Annette (1986). Trust and Antitrust. Ethics, 96(), 231-260. https://doi. org/10.1086/292745

Baird, Davis (2004). Thing Knowledge: A Philosophy of Scientific Instruments. University of California Press.

Bird, Alexander (2014). When Is There a Group That Knows? Distributed Cognition, Scientific Knowledge, and the Social Epistemic Subject. In Jennifer Lackey (Ed.), Essays in Collective Epistemology (42-63). Oxford University Press. https://doi.org/10.1093/ac prof:oso/9780199665792.003.0003

Burge, Tyler (1993). Content Preservation. Philosophical Review, 102(4), 457-488. https:// doi.org/10.2307/2185680

Burge, Tyler (1997). Interlocution, Perception, and Memory. Philosophical Studies, 86(1), 21-47. https://doi.org/10.1023/A:1004261628340

Burge, Tyler (2013). Postscript: 'Content Preservation'. In Cognition through Understanding: Self-Knowledge, Interlocution, Reasoning, Reflection (254-284). Oxford University Press.

Cohen, Jonathan (1980). Some Comments on Third World Epistemology. British Journal for the Philosophy of Science, 31(2), 175-18o. https://doi.org/10.1093/bjps/31.2.175

Currie, Gregory (1978). Popper's Evolutionary Epistemology: A Critique. Synthese, 37(3), 413-431. https://doi.org/10.1007/BF00873248

Earman, John and Clark Glymour (1980). Relativity and Eclipses: The British Eclipse Expeditions of 1919 and Their Predecessors. Historical Studies in the Physical Sciences, 11(1), 49-85. https://doi.org/10.2307/27757471

Faulkner, Paul (2000). The Social Character of Testimonial Warrant. Journal of Philosophy, 97(11), 581-601. https://doi.org/10.2307/2678453

Faulkner, Paul (2006). Understanding Knowledge Transmission. Ratio, 19(2), 156-175. https://doi.org/10.1111/j.1467-9329.2006.00317.x 
Faulkner, Paul (2007). On Telling and Trusting. Mind, 116(464), 875-902. https://doi. org/10.1093/mind/fzm875

Faulkner, Paul (2011). Knowledge on Trust. Oxford University Press. https://doi. org/10.1093/acprof:oso/9780199589784.001.0001

Faulkner, Paul (2013). Two-Stage Reliabilism, Virtue Reliabilism, Dualism and the Problem of Sufficiency. Social Epistemology and Reply Collective, 2(8), 121-138.

Fricker, Miranda (2012). Group Testimony? The Making of a Collective Good Informant. Philosophy and Phenomenological Research, 84(2), 249-276. https://doi.org/10.1111/ j.1933-1592.2011.00565.x

Gilbert, Margaret (1989). On Social Facts. Princeton University Press.

Gilbert, Margaret (2003). The Structure of the Social Atom: Joint Commitment as the Foundation of Human Social Behavior. In Frederick Schmitt (Ed.), Socializing Metaphysics: The Nature of Social Reality (39-64). Rowman \& Littlefield.

Ginet, Carl (1975). Knowledge, Perception, and Memory. Reidel. https://doi.org/10.1007/97894-010-9451-1

Goldberg, Sanford (2010). Relying on Others. Oxford University Press. https://doi. org/10.1093/acprof:oso/9780199593248.001.0001

Graham, Peter (2006). Can Testimony Generate Knowledge? Philosophica, 78(2), 105-127.

Hardwig, John (1985). Epistemic Dependence. The Journal of Philosophy, 82(7), 335-349. https://doi.org/10.2307/2026523

Hinchman, Edward (2005). Telling as Inviting to Trust. Philosophy and Phenomenological Research, 70(3), 562-587. https://doi.org/10.1111/j.1933-1592.2005.tb00415.x

Hutchins, Edwin (1995). Cognition in the Wild. The MIT Press.

Jones, Karen (1996). Trust as an Affective Attitude. Ethics, 107(1), 4-25. https://doi. org/10.1086/233694

Knorr-Cetina, Karin (1999). Epistemic Cultures - How the Sciences Make Knowledge. Harvard University Press.

Kukla, Rebecca (2012). Author TBD: Radical Collaboration in Contemporary Biomedical Research. Philosophy of Science, 79(5), 845-858. https://doi.org/10.1086/668042

Lackey, Jennifer (1999). Testimonial Knowledge and Transmission. Philosophical Quarterly, 49(197), 471-490. https://doi.org/10.1111/1467-9213.00154

Lackey, Jennifer (2008). Learning from Words - Testimony as a Source of Knowledge. Oxford University Press. https://doi.org/10.1093/acprof:oso/9780199219162.001.0001

Lackey, Jennifer (2014). A Deflationary Account of Group Testimony. In Jennifer Lackey (Ed.), Essays in Collective Epistemology (64-94). Oxford University Press. https://doi. org/10.1093/acprof:oso/9780199665792.003.0004

List, Christian and Philip Pettit (2011). Group Agency. Oxford University Press. https:// doi.org/10.1093/acprof:oso/9780199591565.001.0001

Ludwig, Kirk (2014). Proxy Agency in Collective Action. Noûs, 48(1), 75-105. https://doi. org/10.1111/nous.12013

Miller, Boas (2015). Why (Some) Knowledge Is the Property of a Community and Possibly None of Its Members. The Philosophical Quarterly, 65(260), 417-441. https://doi. org/10.1093/pq/pqv025

Moran, Richard (2005). Getting Told and Being Believed. Philosophers' Imprint, 5(5), 1-29. O’Hear, Anthony (1980). Karl Popper. Routledge \& Kegan Paul.

Popper, Karl (1972a). Epistemology without a Knowing Subject. In Objective Knowledge: An Evolutionary Approach (106-152). Clarendon Press. 
Popper, Karl (1972b). Objective Knowledge; an Evolutionary Approach. Clarendon Press.

Popper, Karl (1972C). On the Theory of the Objective Mind. In Objective Knowledge: An Evolutionary Approach (153-190). Clarendon Press.

Tollefsen, Deborah (2007). Group Testimony. Social Epistemology, 21(3), 299-311. https:// doi.org/10.1080/02691720701674163

Tollefsen, Deborah (2009). Wikipedia and the Epistemology of Testimony. Episteme, 6(1), 8-24. https://doi.org/10.3366/E1742360008000518

Tuomela, Raimo (2013). Social Ontology: Collective Intentionality and Group Agents. Oxford University Press. https://doi.org/10.1093/acprof:oso/9780199978267.001.0001

Wright, Stephen (2016). The Transmission of Knowledge and Justification. Synthese, 193(1), 293-311. https://doi.org/10.1007/s11229-015-0760-y 